\title{
Containing Airborne Transmission of COVID-19 and Its Implications for Global Economic Recovery
}

\author{
http://doi.org/10.21272/bel.5(1).81-88.2021
}

Achintya Ray, ORCID: https://orcid.org/0000-0003-4269-0268

$\mathrm{PhD}$ in Economics, Professor of Economics, Tennessee State University, Nashville, TN, USA

\begin{abstract}
COVID-19 was first reported in December 2019 in Wuhan, China; however, it took international health experts another six months to establish the airborne nature of transmission of the disease. The transmission of the infection through aerosolized virus particles opens a new frontier in global pandemic control initiatives. It necessitates the need for appropriate economic policies to end the COVID-19 recession in most parts of the world. Mass vaccination and herd immunity are potent tools in combatting the challenge of COVID-19. Global vaccination against the disease is also gaining momentum. However, new variants and infection surges threaten to undermine critical gains. Furthermore, complete vaccination of the world population may be many years away. Therefore, it is essential to design public policies and business strategies in a world of great uncertainty. Understanding the airborne transmission of coronavirus will help business leaders craft meaningful operational procedures to protect their stakeholders and minimize costly business disruptions. It will also help the policymakers to avoid economically costly lockdowns. International success in indoor air purification, outdoor air pollution mitigation, widespread adoption of hand hygiene, and universal mask usage can significantly help pandemic control and increase the efficacy of various pandemic control measures. Controlling the pandemic may help countries in opening their economies and kickstarting global travel in the post-COVID-19 world. Such actions may also help in lessening the global burden of many other respiratory diseases. They may, in turn, save countless lives while dramatically reducing premature deaths. Such health gains may be conducive towards boosting GDP, decreasing healthcare costs, increasing productivity, and improving health equities. Controlling the COVID-19 pandemic remains the prime directive of all global public policy measures. Investments in aerosolized virus particle transmission mitigation offer a unique opportunity to achieve health improvement goals whose positive impacts may remain potent for generations to come.
\end{abstract}

Keywords: COVID-19, Airborne Transmission, Aerosolizes Virus Particle, Pandemic Control, Respiratory Diseases, Pandemic Policy, Economics of Respiratory Diseases.

JEL Classification: I12, I15, I18, F47, R41, Z38.

Cite as: Ray, A. (2021). Containing Airborne Transmission of COVID-19 and Its Implications for Global Economic Recovery. Business Ethics and Leadership, 5(1), 81-88. http://doi.org/10.21272/bel.5(1).81-88.2021.

Received: 31 January 2021

Accepted: 10 March 2021

Published: 30 March 2021

Copyright: (C) 2021 by the author. Licensee Sumy State University, Ukraine. This article is an open access article distributed under the terms and conditions of the Creative Commons Attribution (CC BY) license (https://creativecommons.org/licenses/by/4.0/).

\section{Introduction}

The 2019 Coronavirus pandemic (COVID-19) has now reached over 200 countries, infecting over 119 million people, and taking the lives of over 2.7 million individuals worldwide. It is easily one of the most worrisome global pandemics in recent history and certainly the most severe since the 1918-20 influenza pandemic that killed an estimated 50-100 million people worldwide. About 98.2 million of the known infections are already resolved. The infected person either recovered from the illness or died from it - the effective case fatality at about $2.5 \%$. About 21 million individuals are still struggling with the disease, of which about $1 \%$ (over 90,000) remain critically ill. It is safe to say at this point the COVID-19 pandemic is far from being over. However, significant gains have been made in the last year (Worldometer, 2021). The increasing availability of safe and highly effective vaccines will help us reduce the pandemic's impact further. This is the third global spread of coronavirus in the $21^{\text {st }}$ century. The two earlier iterations SARS-CoV of 2002 and MERS-CoV of 2012, also caused severe respiratory problems among the affected, justifying their nomenclature (SARS: Sudden Acute Respiratory Syndrome and MERS: Middle Eastern Respiratory Syndrome). 
The current version of the infections driven by SARS-CoV-2 possesses infectivity (R0) between 3.6 and 4 , which is considerably more than the influenza virus, where the infectivity usually stands between 1.4 to 1.6. Furthermore, SARS-CoV-2 retains its infectivity for a prolonged period peaking early in the infection phase and remaining potent for days and weeks after resolution. SARS-CoV-2 is an RNA virus (32 KB genome) capable of significantly evolved adaptive capabilities and exhibits frequent mutations making any definitive control of the disease a problematic proposition (Papa et al., 2020). The COVID-19 pandemic has wreaked considerable havoc with the global economy in general and the American Economy in particular. Current estimates suggest that the pandemic has led to a loss of 11.5 million American jobs at its worst, often pushing the unemployment rates well into the double digits in many states in the USA during the summer months. Although the labor market conditions show modest signs of recovery since then, the country still has a considerable distance to go before the lost jobs are recovered, partially as many believe that some lost jobs are lost forever (US Bureau of Labor Statistics, 2021).

Other developed countries have also suffered significantly. Between 1 in 5 to 2 in 5 employees lost jobs and furloughed through the pandemic in countries like the UK, Germany, Italy, and France. Nearly all countries worldwide have experienced significant economic contraction frequently coupled with shocking levels of decline in consumer demand falling somewhere between 30\% and 80\% (Jones et al., 2021). Preliminary estimates suggest that the SARS-CoV-2 pandemic has significantly affected the economies in South Asia, like in India. Indian GDP growth fell by $9.3 \%$ between April to June 2020, and lockdowns cost the economy an estimated \$26 billion (Statista Research Department, 2020). Understanding the transmission mechanism of the $S A R S-C o V-2$ is vital to crafting appropriate economic policies, public health campaigns, and business procedures that create an ethical, respectful, productive, and safe economic environment where all stakeholders can participate transparently and gainfully. Without transparency, confusion in financial and business activityrelated transactions may impair the participants' safety and attract sub-optimal policy responses that perpetuate unnecessary and economically wasteful lockdowns.

In this article, several aspects of the airborne nature of the SARS-CoV-2 transmission and the consequent continuation of the pandemic are connected to inform managerial decision-making and encourage appropriate policy responses. Although several high-efficiency vaccines are getting used, the COVID-19 pandemic remains far from getting over. We may be years away from eliminating the pandemic. New variants of the virus continuously threaten the fragile progress being painfully achieved so far. What should the policymakers do if most of the population remains vulnerable well into the future? What can the policymakers and business leaders do to keep their citizens and stakeholders safe while maintaining as much progress towards a postCOVID-19 world as possible? Recognizing the various ways SARS-CoV-2 can transmit will offer us credible pathways to tame the pandemic and return to a sustainable economic growth path. Arresting the virus's transmission is a prerequisite to stop the mass infection, reduce morbidity, and lower mortality. That is also important to reduce the chances of costly prolonged lockdowns and business disruptions.

There are three essential topics that are considered in this paper:

$>$ How does the understanding of the airborne transmission of SARS-CoV-2 shape our view of the pandemic and inform our decision-making?

$>$ How can the control measures combat airborne transmission aid the progress made through vaccination and local controls?

$>$ How can the global economy save enormous healthcare costs stemming from particulate air pollution and other respiratory diseases by putting in place mitigation measures to combat airborne SARS-CoV-2 transmission?

\section{Literature Review}

One of the significant ways that the countries worldwide attempted to reign in the virus was by mandating shelter in place or lockdowns that measurably curtailed inter-personal and community exposures. Such lockdowns also reduced global travel and trade dramatically and disrupted the worldwide supply chains. It was widely believed that breaking the virus's transmission chain through lockdowns and population movement controls would help keep the infection rate manageable by arresting the virus's transmission to the vulnerable population. The success of such large-scale lockdowns remains a continued area of debate and will like to stay that way for years to come. The success of the recommendations of social distancing and mandating movement restrictions depends on how the virus transmits through the communities. Such transmissions are challenging to arrest if they happen through airborne channels. Air purification, filtration, and respiratory barriers will likely be the critical tools against a pandemic's successful containment. 
The Centers for Disease Control in the USA have declared SARS-CoV-2 to be an airborne infection. More formally, airborne infections are defined to be "infections capable of being transmitted through exposure to infectious, pathogen-containing, small droplets and particles suspended in the air over long distances and that persist in the air for long times" (US Centers for Disease Control, 2020). Given the transmission's airborne nature, the chances of spreading the SARS-CoV-2 infection rise significantly in indoor environments, especially in poorly ventilated areas that are likely to be highly congested. Furthermore, the viral load and infectivity rates are considerably higher in crowded places, mainly because airborne transmission can travel further than 6-ft and through ventilation systems. Aerosolized virus particles can contaminate large volumes of space, simultaneously increasing the vulnerability of many people. The probability of such contamination dramatically increases in closed places like offices and shopping malls and mass transport systems that are not well ventilated but critical to modern economic lives. Interestingly, the airborne nature and survivability of the coronavirus have long attracted academic attention. Despite the deep research interest in aerosolized virus transmission, many of the relevant studies (Booth et al., 2005; Dowell and Simmerman, 2004; Ijaz et al., 1985) might have been ignored during the early policymaking phases.

Given those studies, early-stage recognition that coronavirus was airborne might have led to widespread mask mandates right from the beginning. Doing so could have significantly slowed the progression of the pandemic and might have saved countless lives. Furthermore, considerable efforts could have been made to sanitize the circulating indoor air, making the indoor environment cleaner for all users; especially in nursing and long-term care facilities where the vulnerable population's density in close proximity is very high. Recognition of SARSCoV-2's airborne transmission raises crucial questions about the constraints that need to be placed on various economic activities, especially when such actions can be allowed in a cleaner environment while practicing appropriate hygiene habits. The implications of such restrictions on a global economic recovery must also be contemplated with appropriate rigor before policies are crafted and implemented.

Aerosolized virus particles affect all economic activities involving many people interacting over a closed space. Some of those activities include mass transport, large and poorly ventilated office spaces, shopping malls, crowded hospitals, large educational institutions, closed restaurants, movie theaters, trans-oceanic cruises, entertainment venues, social functions, etc. Concerns about aerosolized SARS-CoV-2 particles should remain a fundamental consideration for policymaking. Recent news suggests that a vaccine for $S A R S-C o V-2$ may be about $90 \%$ effective based on preliminary and incomplete data. Much more insights regarding the longterm efficacy, safety, and impacts on immunity will be available in the future. Such knowledge could not be generated especially given the rapidity with which these vaccines were developed (Gelles, Thomas and Zimmer, 2020). Large parts of the population, like the children, still do not have an approved vaccine that they can use (Mandivilli, 2020b).

Even if the studies are complete and reliable and high-efficiency vaccines are available for everyone, it might take a considerable period for that vaccine to reach all corners of the world and all different populations. Recent research also suggests that the SARS-CoV-2 will remain an endemic problem confronting humanity for generations to come. Therefore, far longer-term planning and preparations will be needed to keep the global economy open and safe (Phillips, 2021). Furthermore, it is unclear whether any such vaccination will provide immunity only over a limited window of time or require periodic booster doses to offer proper immunity. The long-term effects of the vaccine on human biology remain to be studied. Over 1,600 individuals have already lost their lives due to the adverse effects of the SARS-CoV-2 vaccine. More research will be necessary to ensure that the vaccines remain safe and without significant side effects, and that research might take several years to accomplish that (US Centers for Disease Control, 2021).

By design, a large cross-section of economic activities is often organized to accommodate a large volume of participants to decrease marginal costs, especially given the high fixed costs of managing such activities. Also, economies suffer from severe capacity constraints, and a decline in participation volume or consumer density may be detrimental to any cost reduction initiative. The lack of ability to spread the high fixed costs over a larger volume of consumers can seriously threaten many businesses' financial viability. For example, airlines will be financially affected if they are mandated to keep the middle seat empty and carry only a fraction of passengers to maintain social distancing between the passengers. Patronage of restaurants will significantly drop if they cannot accommodate much clientele, huge groups for a single event like weddings, birthdays, office meetings, and other celebrations. Office buildings will lose their economies of scale if they remain half empty. Commercial real estate is already facing solid challenges given the movement to working from home. Not enough train cars are available to ferry suburban passengers during peak hours if the train cars are only mandated to carry a small number of passengers. 
As the examples above show, mandating social distancing can render many businesses unprofitable, leading to business closures, rising unemployment, an excess burden on the governments, declining tax revenues, and worsening budget situations. The airborne nature of the SARS-CoV-2 transmission complicates affairs even more. Social distancing may not be sufficient to put downward pressure on the rate of spread of infection, making economy-wide opening plans hard to approve and sustain. That itself exacerbates working conditions for businesses and leads to significant business losses. For example, aerosolized virus particles can travel large distances and infect office goers even on different floors if the building is poorly ventilated. This increased probability of infection does not go away for the occupants, even if only half of the building remains occupied at any given period.

Furthermore, the infection's extent may remain imprecisely measured since the SARS-CoV-2 may take days to manifest itself in disease. Many people remain silent carriers in that they do not have the disease even after catching the virus. Even if only a tiny fraction of the shopping malls can be occupied by the patrons, airborne transmission through the ventilation system can infect people throughout the mall. This infection can happen even when the patrons are physically far away from one another. Aerosolized viral particles circulating through the air can contaminate many passengers in air-conditioned train cars, cruise ships, and airplanes, complicating the viability of resuming a safe global transport system.

Vaccination for COVID-19 has been going on a dramatic war footing in many parts of the world. Millions of people are getting vaccinated every day. Close to half a billion people from all over the world have received the vaccine already (Our World in Data, 2021). Tens of millions of people have successfully recovered from the infection even without a vaccine (Worldometer, 2021). US National Institutes of Health reports a longterm immunity of up to eight months following the infection (National Institutes of Health, 2021). Initial reports also suggest that the immunity of the recovered patients may last for years (Mandivilli, 2020b). Also, despite the gains made by mass vaccination, $S A R S-C o V-2$ threatens to remain an endemic challenge for generations to come (Phillips, 2021).

Complete vaccination for the global population remains years away. Furthermore, billions of children remain not vaccinated, and they will probably need vaccination for years to come as they become adults. Therefore, thinking about broader management issues may be essential to achieve maximum policy efficacy (Mandivilli, 2020a). Although relatively little data exists regarding the growth of personal protective equipment manufacturing following the pandemic, initial estimates suggest that the global market may experience about $60 \%$ increase between 2019 to 2026 from $\$ 50$ billion to $\$ 80$ billion (Singh, 2020). Given the discussion above, any public policy in the face of the airborne nature of SARS-CoV-2 transmission should involve multipronged defenses.

\section{Methodology and Research Methods}

A qualitative method through appropriate literature search is adopted for this research to identify four distinct yet complementary strategies. These strategies can effectively combat airborne infection, create a safer environment, and increase public health programs' effectiveness. They can also deliver positive externality to improve global health outcomes and reduce healthcare costs. The proposed interventions are organized to check four hypotheses.

Table 1. Hypotheses Examined in the Article

\begin{tabular}{|l|l|}
\hline $\begin{array}{l}\text { Hypothesis } 1(\boldsymbol{H 1}) \text { : Requiring universal mask usage will reduce } \\
\text { the morbidity, mortality, and spread of the SARS-CoV-2 } \\
\text { pandemic. }\end{array}$ & $\begin{array}{l}\text { Hypothesis 2 (H2): Implementing overall hand hygiene will } \\
\text { reduce the morbidity, mortality, and spread of the SARS-CoV- } \\
2 \text { pandemic. }\end{array}$ \\
\hline $\begin{array}{l}\text { Hypothesis 3 }(\boldsymbol{H 3}) \text { : Adopting highly efficient air filtration and } \\
\text { air sanitizing systems will reduce the morbidity, mortality, and } \\
\text { spread of the SARS-CoV-2 pandemic. }\end{array}$ & $\begin{array}{l}\text { Hypothesis 4 (H4): Adopting mask mandate, hand hygiene, air } \\
\text { filtration, and air sanitization will be effective in delivering } \\
\text { positive externality in reducing the morbidity, mortality, and } \\
\text { spread of other airborne infections like influenza and } \\
\text { tuberculosis. }\end{array}$ \\
\hline
\end{tabular}

Source: Compiled by the author

To capture the global surge in the demand for personal protective equipment, including but not limited to air filtration system, indirect evidence is presented by modeling the rise in stock prices for several major players in the market. The selected companies are 3M (MMM), Honeywell International Inc. (HON), Delta Plus Group (DLTA.PA), DuPont de Nemours, Inc. (DD), Ansell Limited (ANN.AX), MSA Safety Incorporated (MSA), Lakeland Industries, Inc. (LAKE). Closing stock prices of the companies are collected for March 23, 2020 and March 23, 2021. Percentage change in the stock price is presented in a graphical format. 


\section{Results}

Hypothesis 1 (H1): Requiring universal mask usage will reduce the morbidity, mortality, and spread of the SARS-CoV-2 pandemic.

The use of walls in controlling the transmission of airborne pathogens was first proposed in the 1930s (Wells, 1934). This issue received widespread attention during the SARS-CoV-1 and H1N1 pandemic too (Chao at el., 2009). Various kinds of masks have been found to be effective against airborne pathogen transmission, although the efficiency of those masks can vary widely (Lai et al., 2012). Recent research suggests that using two masks instead of one can significantly improve protection against aerosolized virus transmission (Cleveland Clinic, 2020). Requiring or strongly encouraging universal mask usage can considerably reduce the transmission of SARSCoV-2 even when the virus particles are aerosolized. Lowering the transmission will help keep the overall spread of the virus under control. This will reduce the pressure on the policymakers to implement costly lockdowns in various geographic regions. Recent results suggest that greater mask usage coupled with physical distancing has the highest probability of controlling the pandemic (Rader et al., 2021).

Hypothesis 2 (H2): Implementing overall hand hygiene will reduce the morbidity, mortality, and spread of the SARS-CoV-2 pandemic.

Masks may be supplemented by regular hand washing using soap and water. Hand hygiene may be improved by using alcohol-based hand sanitizers and sanitizing high touch areas like doorknobs, elevator buttons, bathroom fixtures, stair guards, mass transport seats, etc. Recent studies have also found that ".... facemasks and facemasks plus hand hygiene may prevent infection in community settings, subject to early use and compliance" (MacIntyre and Chughtai, 2015). Hand hygiene remains a very tool in the fight against the pandemic, recent research found (Gupta and Shari, 2020).

Hypothesis 3 (H3): Adopting highly efficient air filtration and air sanitizing systems will reduce the morbidity, mortality, and spread of the SARS-CoV-2 pandemic.

A highly efficient indoor air purification system should also remain a cornerstone of the strategy while the world combats the SARS-CoV-2. Air purifiers armed with High-Efficiency Particulate Air (HEPA) filters can screen SARS-CoV-2 with a diameter of about 0.125 microns. That size is considerably more prominent than the 0.01 micron and above what the HEPA can filter (Hefferman, 2020). A NASA study released in 2016 confirms the high protectiveness of the HEPA filter. (Agui, Perry and Vijaykumar, 2016) Arming the air purification system with Ultraviolet-C $(U V-C)$ irradiation chamber can add an extra layer of protection to the indoor air environment. The UV-C irradiation chamber can significantly purify the air by deactivating virus, bacteria, and mold spores as the air travel through the section (UV-C Air Purifiers for COVID-19, 2021). The HEPA filters may screen the remaining aerosolized virus particles.

Hypothesis 4 (H4): Adopting mask mandate, hand hygiene, air filtration, and air sanitization will deliver positive externalities in reducing the morbidity, mortality, and spread of other airborne infections like influenza and tuberculosis.

There will likely be significant externalities stemming from efforts to contain transmission of virus particles. The global burden of diseases may see a downward trend from SARS-CoV-2 management strategies, especially related to influenza and other respiratory diseases and deaths. For example, about half a million people die globally from influenza-related complications each year, while the disease results in about 3-5 million severe illnesses. This represents about $2 \%$ of the global respiratory deaths, and about two-thirds of the affected individuals belong to the $\geq 65$ age category (Paget et al., 2019). Influenza-related morbidity and mortality inflict significant worldwide economic impact (Chaiyakunapruk et al., 2018).

Recent studies suggest that globally, about 4 million people die prematurely from various chronic respiratory diseases. About 3 million people die from Chronic Obstructive Pulmonary Disease (COPD), 334 million people have Asthma, 10 million people develop tuberculosis and related diseases, and 1.4 million people die from it. Millions more perish from Respiratory diseases like Pneumonia. These diseases and mortalities also inflict high worldwide economic costs (Forum of International Respiratory Society, 2017). Many respiratory diseases are worsened by poor air quality that significantly impairs the human lungs' healthiness and weakens the immune system. Controlling air pollution assumes a significant policy thrust given the global SARS-CoVtwo pandemic. As the recent research has shown, “... about 15\% of deaths worldwide from COVID-19 could be attributed to long-term exposure to air pollution. In Europe, the proportion was about 19\%, in North America it was 17\%, and in East Asia about 27\%" (MSN News, 2020). 
This line of research also points to the significant twin impact or lower burden of global respiratory diseases and lower mortality from $S A R S-C o V-2$ that may be derived by implementing some of the same steps that can be used to combat the airborne nature of SARS-CoV-2 transmission (Pozzer et al., 2020). Furthermore, considering that environmental pollution in general and air pollution particularly affects vulnerable communities and minorities in disproportionate numbers, measures to control airborne pathogen transmission may significantly improve health equities while controlling the pandemic and harvesting associated economic gains (Havard et al., 2009; Morello-Frosch et al., 2002; O'Neill et al., 2003). Although no direct test is available to measure the recognition of the need for personal protective equipment, it may be gauged by analyzing the performance of the stocks of major players in that market. Twelve-month changes in stock price of 3M (MMM), Honeywell International Inc. (HON), Delta Plus Group (DLTA.PA), DuPont de Nemours, Inc. (DD), Ansell Limited (ANN.AX), MSA Safety Incorporated (MSA), Lakeland Industries, Inc. (LAKE) are presented in the chart below. These companies have significantly benefitted from the surge in demand for personal protective equipment including but not limited to air filtration system.

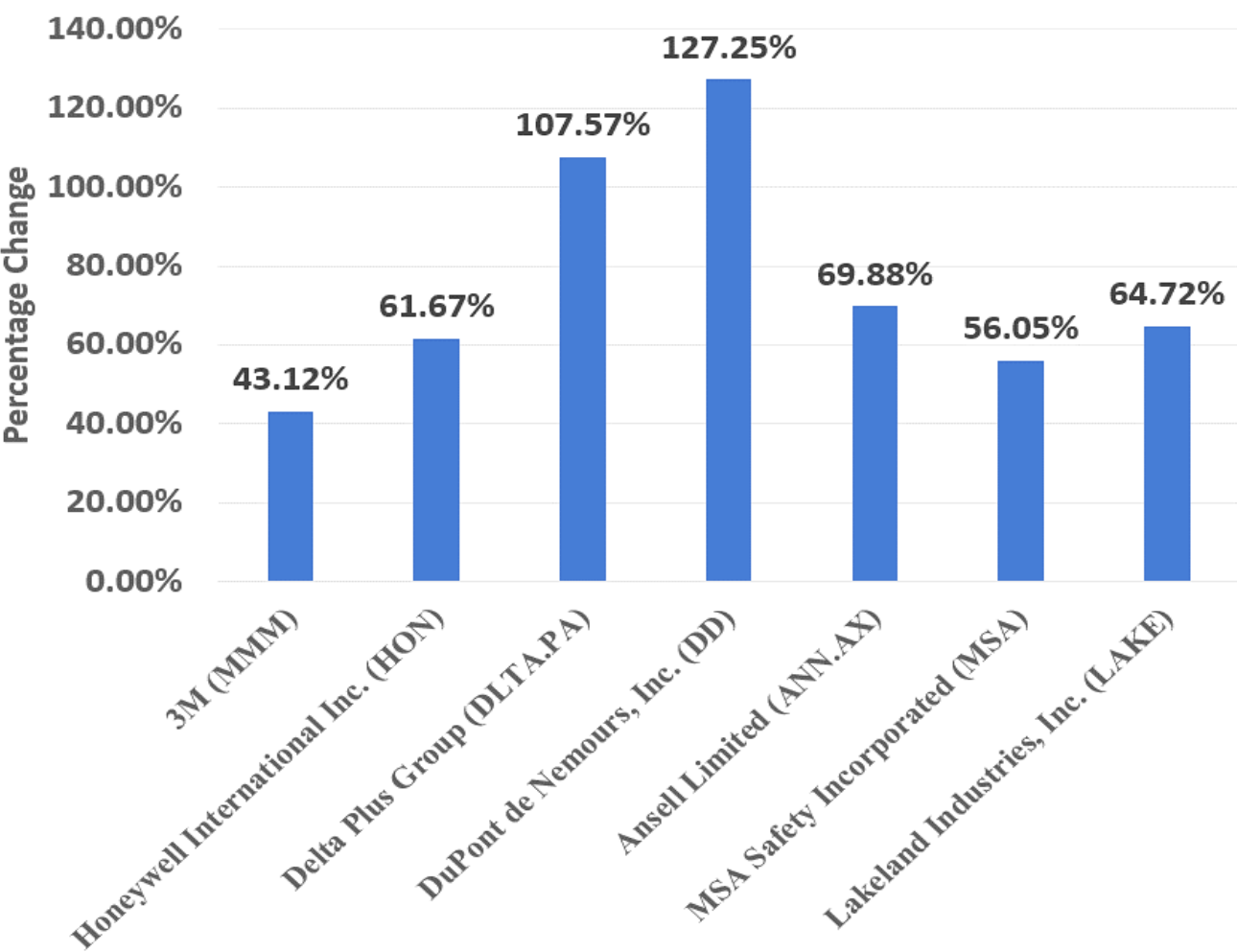

Figure 1. Percentage Change in the Stock Prices of Major Players in the Personal Protective Equipment Market (March 23, 2020 to March 23, 2021)

Source: Stock price data were collected from Yahoo, Finance

\section{Conclusions}

A global collaboration to design and implement policies aimed towards controlling the SARS-CoV2 pandemic (keeping in mind the airborne nature of transmission) will help the countries in pandemic control. Also, it will also help kickstart the global economy and regain a sustainable growth path. Such efforts will also help us reengage with the way to a broad-based economic recovery. The same policies may also help reduce the transmission of other airborne pathogens. It will further reduce the global burden of respiratory diseases and premature deaths. Simple guidelines like indoor air pollution mitigation, environmental air pollution mitigation, near-universal mask usage, etc., may complement other public health policies like mass vaccination and hand hygiene to add significantly to the global economy in a short period.

Funding. This research received no external funding.

\section{References}

1. Booth, T.F., Kournikakis, B., Bastien, N., Ho, J., Kobasa, D., Stadnyk, L., \& Mederski, B. (2005). Detection of airborne severe acute respiratory syndrome (SARS) coronavirus and environmental contamination in SARS outbreak units. The Journal of Infectious Diseases, 191(9), 1472-1477. https://doi.org/10.1086/429634. 
2. Cleveland Clinic (2021). Should You Wear Two Masks to Prevent the Spread of COVID-19? https://health.clevelandclinic.org/should-you-wear-two-masks-to-prevent-the-spread-of-covid-19? Accessed March 12, 2021.

3. Chaiyakunapruk, N., Kotirum, S., Newall, A.T., Lambach, P., Hutubessy, R.C.W. (2018). Rationale and opportunities in estimating the economic burden of seasonal influenza across countries using a standardized WHO tool and manual. Influenza and Other Respiratory Viruses, 12, 13-21. https://doi.org/10.1111/irv.12491.

4. Chao, C.Y.H., Wanb, M.P., Morawska, L., Johnson, G.R., Ristovski, Z.D., Hargreaves, M., Mengersen, K., Corbett, S., Li, Y., Xie, X., Katoshevski, D. (2009). Characterization of expiration air jets and droplet size distributions immediately at the mouth opening. J. Aerosol Sci., 40, 122-133. https://doi.org/10.1016/j.jaerosci.2008.10.003.

5. Dowell, Scott F., Simmerman, James M., Erdman, Dean D., Wu, Jiunn-Shyan Julian, Chaovavanich Achara, Javadi Massoud, Jyh-Yuan Yang, Anderson, Larry J., Tong Suxiang, Ho Mei Shang (2004). Severe acute respiratory syndrome coronavirus on hospital surfaces. Clinical Infectious Diseases, 39(5), 652-657. https://doi.org/10.1086/422652.

6. Forum of International Respiratory Societies (2017). The Global Impact of Respiratory Disease - Second Edition. Sheffield, European Respiratory Society. Print ISBN: 9781849840873 ; e-ISBN: 9781849840880.

7. Gupta, Mohit Kumar, and Shari R. Lipner. (2020). Hand hygiene in preventing COVID-19 transmission. Journal of American Academy of Dermatology, 82, 1215-1216. Available at: https://cdn.mdedge.com/files/s3fs-public/Gupta\%202020\%20CT105005233.pdf.

8. Havard, S., Deguen, S., Zmirou-Navier, D., Schillinger, C., Bard, D. (2009). Traffic-related air pollution and socioeconomic status a spatial autocorrelation study to assess environmental equity on a small-area scale. Epidemiology, 20, 223-30. DOI:10.1097/EDE.0b013e31819464e1.

9. Hefferman, T. (2020). Can HEPA Air Purifiers Capture the Coronavirus? New York Times, https://www.nytimes.com/wirecutter/blog/can-hepa-air-purifiers-capture-coronavirus/. Accessed March 17, 2021.

10.Ijaz, M.K., Brunner, A.H., Sattar, S.A., Nair, R.C., \& Johnson-Lussenburg, C.M. (1985). Survival characteristics of airborne human coronavirus 229E. Journal of General Virology, 66(12), 2743-2748. https://doi.org/10.1099/0022-1317-66-12-2743.

11.Jones, L., Palumbo, D., Brown, D. (2021). Coronavirus: How the pandemic has changed the world economy, BBC. https://www.bbc.com/news/business-51706225. Accessed March 17, 2021.

12.Lai, A.C., Poon, C.K., \& Cheung, A.C. (2012). Effectiveness of facemasks to reduce exposure hazards for airborne infections among general populations. Journal of the Royal Society, Interface, 9(70), 938-948. https://doi.org/10.1098/rsif.2011.0537.

13.MacIntyre, C.R., Chughtai, A.A. (2015). Facemasks for the prevention of infection in healthcare and community settings. British Medical Journal, 350, h694. DOI:10.1136/bmj.h694.

14.Mandavilli, A. (2020a). Covid Vaccines for Kids Are Coming, but Not for Many Months, New York Times. https://www.nytimes.com/2021/02/12/health/covid-vaccines-children.html. Accessed March 12, 2021.

15.Mandavilli, A. (2020b). Immunity to the Coronavirus May Last Years, New Data Hint, New York Times, https://www.nytimes.com/2020/11/17/health/coronavirus-immunity.html. Accessed March 12, 2021.

16.Morello-Frosch, R., Pastor, M., Porras, C., Sadd, J. (2002). Environmental justice and regional inequality in southern California: implications for future research. Environmental Health Perspectives, 110, 149-54. https://doi.org/10.1289/ehp.02110s2149.

17.MSN News (2020). Study estimates exposure to air pollution increases COVID-19 deaths by $15 \%$ worldwide. https://www.msn.com/en-in/news/world/study-estimates-exposure-to-air-pollution-increasescovid-19-deaths-by-15-worldwide/vi-BB1aqWOU. Accessed March 12, 2021.

18.National Institutes of Health (2021). https://www.nih.gov/news-events/nih-research-matters/lastingimmunity-found-after-recovery-covid-19. Accessed March 12, 2021.

19.O’Neill, M.S., Jerrett, M., Kawachi, L., Levy, J.L., Cohen, A.J., Gouveia, N. (2003). Health, wealth, and air pollution: advancing theory and methods. Environmental Health Perspectives, 111, 1861-70. https://doi.org/10.1289/ehp.6334.

20.Our World in Data (2021). https://ourworldindata.org/covid-vaccinations. Accessed March 12, 2021.

21.Paget, J., Spreeuwenberg, P., Charu, V., Taylor, R. J., Iuliano, A.D., Bresee, J., Simonsen, L., Viboud, C., \& Global Seasonal Influenza-associated Mortality Collaborator Network and GLaMOR Collaborating Teams (2019). Global mortality associated with seasonal influenza epidemics: New burden estimates and predictors from the GLaMOR Project. Journal of Global Health, 9(2), 020421. https://doi.org/10.7189/jogh.09.020421. 
22.Papa, S.M., Brundin, P., and Fung, V.S. (2020). Impact of the COVID-19 pandemic on Parkinson's disease and movement disorders. Movement Disorders, 35(5), 711-15. https://doi.org/10.1002/mds.28067.

23.Perry, J.L., Agui, J.H., and Vijayakumar, R. (2016). Submicron and Nanoparticulate Matter, Removal by HEPA-Rated Media Filters and Packed Beds of Granular Materials. NASA. Available at: https://www.usairpurifiers.com/media/BSE/NASA-HEPA-report-7-2020.pdf.

24.Phillips, N. (2021). The coronavirus is here to stay - here's what that means. Nature (February 16, 2021). https://www.nature.com/articles/d41586-021-00396-2. Accessed March 12, 2021.

25.Pozzer, A., Dominici, F., Haines, A., Witt, C., Münzel, T., Lelieveld, J. (2020). Regional and global contributions of air pollution to risk of death from COVID-19. Cardiovascular Research, 116(4), 2274-2253. https://doi.org/10.1093/cvr/cvaa288.

26.Rader, B., White, L.F., Burns, M.R., Chen, J., Brilliant, J., Cohen, J., Shaman, J., Brilliant, L., Kraemer, M.U.G., Hawkins, J. B., Scarpino, S.V., Astley, C.M., Brownstein, J.S. (2021). Mask-wearing and control of SARS-CoV-2 transmission in the USA: a cross-sectional study. The Lancet Digital Health, 3(3), e148e157. https://doi.org/10.1016/S2589-7500(20)30293-4.

27.Singh, P. (2020). Pandemic Puts PPE Sector on 7\% Growth Path Through 2026. Plastics Today. https://www.plasticstoday.com/medical/pandemic-puts-ppe-sector-7-growth-path-through-2026. Accessed March 24, 2021.

28.Statista Research Department (2021). Impact of the coronavirus (COVID-19) on the Indian economy statistics \& facts. https://www.statista.com/topics/6304/covid-19-economic-impact-on-india/. Accessed March 17, 2021.

29.Thomas, K., Gelles, D., Zimmer, C. (2020). Pfizer's Early Data Shows Vaccine Is More Than 90\% Effective. New York Times. https://www.nytimes.com/2020/11/09/health/covid-vaccine-pfizer.html. Accessed March 17, 2021.

30.US Centers for Disease Control, Science Brief: SARS-CoV-2 and Potential Airborne Transmission (2020). https://www.cdc.gov/coronavirus/2019-ncov/more/scientific-brief-SARS-CoV-2.html, Accessed March $17,2021$.

31.US Bureau of Labor Statistics (2021). https://www.bls.gov/web/laus/lauhsthl.htm and https://carsey.unh.edu/COVID-19-Economic-Impact-By-State. Accessed March 17, 2021.

32.UV-C Air Purifiers for COVID-19 (year). https://www.usairpurifiers.com/blog/uv-c-air-purifiers-forcovid-19-heres-what-you-need-to-know/. Accessed March 17, 2021.

33.US Centers for Disease Control, Selected Adverse Events Reported after COVID-19 vaccination, https://www.cdc.gov/coronavirus/2019-ncov/vaccines/safety/adverse-events.html. Accessed March 12, 2021.

34.Wells, W.F. (1934). On airborne infection. Study II. Droplets and droplet nuclei. American Journal Hygiene, 20, 611-618. Available at: https://www.cabdirect.org/cabdirect/abstract/19352700487.

35.Worldometer Coronavirus Dashboard (2021). https://www.worldometers.info/coronavirus/. Accessed March 17, 2021. 